\title{
A Minimalist Analysis of Verbal Complementation in Igbo
}

\author{
Matthew Onyebuchi Ndiribe \\ Department of Linguistics, Igbo and Other Nigerian Languages, University of Nigeria, Nsukka, Nigeria
}

\begin{abstract}
The study investigates the verbal complementation in Igbo using the Minimalist perspective. In discussing the subject matter, such concepts as verb complementation, reflexive complementation and infinitival complementation are analysed. The objectives of the study are to find out how co-occurrence restrictions, thematic roles, theta criterion, subcategorisation frame and c-command could play crucial roles in selecting the complements of verbs. The study made use of written data, oral communication and introspection as the methods of data collection. The research adopted the standard Igbo as the area of study. The data are analysed using word- for- word English transliteration and then followed by English semantic gloss. The study discovers that the Igbo verbal complementation obeys the rules of adjacency and c-command. The verbs subcategorise its complements based on the relationships existing between the verbs and the complements. The head verb and its complement establish the path of union and intersection in the syntactic form. The concept of theta criterion determines the true nomenclature of the subjects in linguistic structures.
\end{abstract}

Index Terms - verb complementation, reflexive complementation, infinitival complementation, co-occurrence restrictions, minimalism

\section{INTRODUCTION}

Complementation, that is predication, according to Horie \& Comrie (2000), has intrigued linguists of various theoretical persuasions, from cognitive/functional linguistics to typologists to generativists. After the initial stage of concentrated generative grammatical research on the largely syntactic aspects of English complementation in the 1960s and 1970s (e.g. Rosenbaun,1967; Bresnan 1979), linguists started to take the semantic aspects of complementation serious. An important body of research on the semantics of English complementation emerged in the 1960s and 1970s, e.g. Bolinger (1968,1972,1974), Kiparsky \& Kiparsky (1970), Kartmann (1971), Borkin (1973), Ross(1973), Riddle (1974), Hooper (1975), Kirsner \& Thompson (1976).

In the 1980s, according to Horie \& Comrie (2000), the scope of research on complementation was expanded and enriched by the works of functional typologists e.g. Givón (1980), Nooman (1985), Ranson (1986), Lehman (1988), and Wierzbicka (1988). Especially important is Givón's "binding hierarchy" a typologically based hierarchy of correlation between meaning and form in complementation. According to this hierarchy, the degree of "semantic binding" (i.e. the matrix subject's influence on the event expressed in the complement clause) is closely correlated with the degree of morpho-syntactic independence of the complement clause.

Building on this legacy, the 1990s saw great theoretical enhancement and enrichment of the research on the semantics of English complementation (e.g. Dixon. 1990; Frajzyngier \& Jasperson 1991; Duffley. 1992) as well as of the typologically oriented research on complementation (e.g. Frajzyngier. 1991; Horie. 1993; Dixon. 1995). It must also be noted that formal linguists have continued to investigate complementation and have produced some important work in this area (cf Chomsky. 1986; Rizzi. 1990; Authier. 1991) (cf. Horie \& Comrie, 2000). This study investigates the syntactic aspect of complementation in Igbo using a minimalist perspective as a framework.

The Igbo language in the last four decades has seen an upsurge in the theoretical description of many topical issues about language configuration. In the light of the above, many Igbo scholars notably Emenanjo (1975a, 1975b, 1978 \& 2005), Nwachukwu (1976, 1983, 1984, 1987) Ubahakwe (1976), Uwalaka (1983) have discussed the classification of the Igbo language on the dichotomy of transitivity and otherwise. Emenanjo is of the opinion that the Igbo sentence does not need the dichotomy since, according to him, all Igbo sentences are transitive in nature. But Nwachukwu, Ubahakwe and Uwalaka disagree with Emenanjo and assert that there is the need for the dichotomy since all Igbo sentences are not transitive in nature. They maintain that the Igbo sentences could be analysed on transitive and intransitive line. Emenanjo, in (2005), shifted his argument on the concept of complementation as a way of analysing the Igbo verb and not on transitivity/intransitivity divide. Emenanjo seems to confuse transitivity with complementation. To him, both transitivity and complementation serve one and the same purpose.

Emenanjo (2005) uses the term "complementation" to counter the claims of Ubahakwe (1976) and Nwachukwu (1983) who argue in favour of transitivity in the Igbo syntax ( see Okeke. 2015). He disagrees with the analysis of Ubahakwe and Nwachukwu, since according to him, transitivity is a surface structure feature, which does not help to classify Igbo verbs according to the complements they select. Emenanjo (2005) does not go deep to highlight the intricacies of complementation as it occurs in world languages. The factor complicating the sub-classification of Igbo 
verbs into transitives and intransitives is the existence of what Nwachukwu, $(1976,1983)$ referred to as inherent complement verbs (ICV) or Inherent verb complement (IVC). These are verbs the citation form of which always includes a nominal element which may or may not be cognate with the verb. Inherent complement verbs (ICV) are classified according to whether they are transitive or intransitive or unmarked. Another term is what Nwachukwu (1983) calls Bound verb complement (BVC) or what Emenanjo (1975) referred to as Bound cognate noun (BCN) which is a part of a complex verb. This adds emphasis to the verb. This is to say that BVC functions as an emphasiser. This background alludes to the fact that some type of researches have been carried out on some aspects of Igbo syntax but none of the scholars did exactly what is intended to be carried out in this study on complementation. This study focuses primarily on verb complementation using the framework of Minimalism.

The objective of this study is to use the concepts of co-occurrence restrictions, thematic roles, theta criterion and ccommand in analyzing verb complementation in the Igbo language.

The study is organised in the following order: 1 introduces the basic assumption of complementation; section 2 overviews the framework of minimalism, section 3 highlights the basic concepts that underlie this study; section 4 discusses the subject matter of verb complementation using various forms of verb complementations and their analyses. Section 5 shows the findings and wraps up the study.

\section{Minimalist PROGRAM}

This study adopts Minimalist Program framework (MP) as proposed in Chomsky (1995, 1998, 2002). MP is the most recent version of the transformational grammar which employs fewer linguistic apparatus to construct syntactic structures. The apparatus are operations Select, Merge and Agree. Operation Select takes required word items from the lexicon and put them in the numeration to build syntactic structure. Numeration is a place where selected items needed for building syntactic structure are stored. The lexical items in the numeration are in turn put together by an operation dubbed Merge (Olaogun 2017). That is, operations Merge and Agree. Given that operation Move is a form of Merge and that movement of features is replaced by Agree, the computational systems that builds the syntactic tree consists of two operations namely, Merge and Agree. Merge is the operation that combines syntactic elements to form larger structures (Radford, 2004). Chomsky later developed a Phase Theory in which he proposes that syntactic structure is built up in phases (with phase including complementiser phrase (CP) and transitive vP). According to him, at the end of each phase, part of syntactic structure already formed undergoes transfer to the phonological and semantic components, with the result that the relevant part of the structure is inaccessible to further operations from that point on. In his words, (Chomsky. 2001, p.5) asserts: "Once all operations which apply within a given phase have been completed, the domain of the phase (i.e the complement of its head becomes impenetrable to further syntactic operations". He calls this condition "Phase Impenetrable Condition". This implies that c-command domain of a phase head is impenetrability to an external probe (i.e A goal which is c-commanded by the head of a phase is impenetrable to any probe c-commanding the phase).

The Minimalist Program (MP) is a development in generative thinking, which emphasises the aim of making statement about language as simple and general as possible (Nwankweagu. 2015). The emphasis is that grammars should be described in terms of the minimal set of theoretical and descriptive apparatus necessary. In other words, all representations and derivational processes should be as simple in terms of the number of devices proposed to account for language phenomena (the principle of economy). The basic tenet of minimalism is elegance. That is, derivation should be as simple and unambiguous as possible. Structures have to restrict to minimum application of rules in their generation. A derivation, according to Radford (2004), is adjudged to be well-formed if it converges at both interface levels: PF and LF, otherwise it crashes. Convergent derivation must also be optional. This means that it satisfies certain natural economy conditions. In other words, a well-formed structure must have followed the most economical path in the course of derivation. It is binary and recursive in nature-building operation which put together selected lexical items from numeration. Operation Merge is of two kinds, external and internal. External Merge involves merge operation that originates from the numeration while internal is a syntactic structure operation that affects syntactic objects that are already introduced into the derivation (Hornstein, Nunes \& Grohmann. 2005, 317). In this study, Phase Theory will be incorporated where necessary in the analysis of our data.

\section{BASIC CONCEPTS OF VERB COMPLEMENTATION}

\section{A. Complementation}

Linguistically, according to Keown (2012), complementation is a linguistic phenomenon wherein the syntactic head of a phrasal category licenses a word, a phrase or a clause to complete its meaning. Crystal (1995) asserts that "the complement completes the action of the verb and hence cannot be dropped off. There are two main parts to consider while studying the process of complementation. These aspects are the complement and the complementiser. For complements, they are licensed or sanctioned in grammar by their heads. This implies that in order to complete the meaning of the phrase or sentence, a complement is needed or essentially required apart from the head in the phrase. Absence of the complement generates ungrammaticality and unacceptability because the syntactic head is in itself unable to express its complete meaning. In other words, the complement is an obligatory part of the phrase or sentence 
that provides semantic content and hence, cannot be dropped off. Complementiser, on its part is a functional category that connects the main or pivotal clause to the subordinate or dependent clause. This is referred to as clausal complementation, while a complementiser can be used to link the main clause of the sentence with the complement clause. Since the number of complementiser in a language is limited, it forms a closed class. In this study, I will dedicate myself to various aspect of verb complementation.

\section{B. Argument Structure}

The term 'argument', according to Gilbea (2002), comes from philosophy, more particularly, from predicate calculus. Sentences are regarded as well-formed propositions that may be true or not in which something is predicated i.e, claimed about another entity or entities. The argument structure of verbs is particularly important in theta theory, which seeks to describe the thematic role that an argument fulfils in individual sentences.

Finch (2000) sees argument as the term used by linguists to describe the role played by particular entities in the semantic structure of sentences. He says that all verbs are said to have arguments. Indeed, it is the number and nature of the arguments that they require, which distinguish them grammatically. In this study, efforts should be made to locate an argument of a verb in order to determine the role of that verb in a sentence structure.

\section{Thematic Roles}

Finch (2000), states that the theta theory is concerned with assigning thematic roles to arguments of verbs. According to him, theta is the name of the Greek letter $\Theta$, which corresponds to 'th' in English, and since theta begins with 'th' it has become standard convention to abbreviate the expression 'thematic role' to $\Theta$-role. In theta theory, continues Finch (2000), theme indicates one of a number of semantic roles which arguments fulfil. Clauses are seen as consisting of propositions or logical statements, which require certain types of argument in order to be acceptable sentences.

Finch (2000) affirms that theta role is more concerned with 'agency' who does what to whom. The essential elements of the theta theory, according to him, differ somewhat among linguists but the following are commonly assumed theta roles:

Agent: a willful, purposeful instigator of an action or event, such as in:

(2) John broke the glass

Experiencer: things that experience internal states, such as perceivers and emoters (subject of verbs like think, believe, love and hate) as in

(3) John thought about the question

In this study, effort will be made to match the theta role a verb plays in a sentence structure to the nomenclature of the verb in the Igbo grammar.

\section{Theta Criterion}

This is a principle of Universal Grammar which specifies that each argument should bear one and only one theta role, and that each theta role associated with a given predicate should be assigned to one and only one argument (Chomsky, 1981, 36). For this to happen, the Predicate-Internal Theta-Marking Hypothesis (PITMH) which states that an argument that is theta-marked (i.e. assigned a theta role) via merger with a predicate, must be in force. That is, they must unit one another. For instance, the structure the police have arrested the suspect has two arguments - the police and the suspect. The subject - the police is DP while the predicate - arrested the suspect is the V-bar. So the complement the suspect is the internal argument of the verb arrested (in the sense that it is the argument contained within the immediate V-bar projection of the verb, and hence is a sister of the verb), whereas the subject the police is the external argument of the verb arrested (in that it occupies a position external to the $\mathrm{V}$-bar constituent which is the immediate projection of the verb arrested) (Radford, 2004).

In consistence with the theta criterion principle, each argument of the structure above is assigned a single theta role which is different from the one assigned to any other argument of the same predicate. In the structure above, the suspect receives the theme argument while the police receive the agent argument.

\section{VERB COMPLEMENTATION IN IGBO}

By verb complementation, it implies the process whereby the verb head triggers various complements. Verbs are lexical governors. As lexical governors, they assign both case and theta functions to other category, especially the nouns. What this implies is that complementation obeys some rules like that of c-command and adjacency. This rule of ccommand states that the head must precede its complement and as such c-commands it. The rule of adjacency stipulates that the head and its subordinate must be close enough without any intervening nodes. The operations Select, Merge and Move will also be applied where appropriate and when necessary. It is important to note that word level heads of the same class can differ in the categories that they combine with, or more precisely, there is a co-occurrence restriction in the complements that verbs take. For instance, in Igbo, we have these sentences:

(4) Òbi tìnye- re ákwụkwọ n'àkpa

Obi put Past book Prep bag 
'Obi put the book in the bag'

Since (4) is a transitive sentence, it is a Phase. The V adjoins the causative light verb $\varnothing$ and the probe searches for the goal. In this case, the unvalued verb searches for the valued goal akwụkwọ. But since the probe is a [+past] verb, it does not have any difficulty in assigning its [+past] value to the goal since past tense agree with any goal. Therefore, the sentence structure receive [+past] interpretation. The outcome of the probe is that the subject Obi is checked as nominative case since the verb must have an external argument as a transitive verb. The unvalued object akwukwo is checked as an accusative case by the valued [+past] verb.

In the structure (4) above, the verb tinyere originates as the head of V of VP ( Obi as its subject) and akwukwo $n$ 'akpa as its complement; and the verb then raises up to adjoin to the strong causative light verb $\varnothing$ heading the vP. The subject Obi in turn originates in spec VP (assigned the role of AGENT by the causative light verb $\varnothing$ ) and then moves up to spec TP to check its strong nominative case feature (cf. Radford, 2004). Once a vP is assembled, Spell out applies to the complement of its head (i.e. DP) and the semantic and phonological components inspect the shipped material as the tree below depicts:

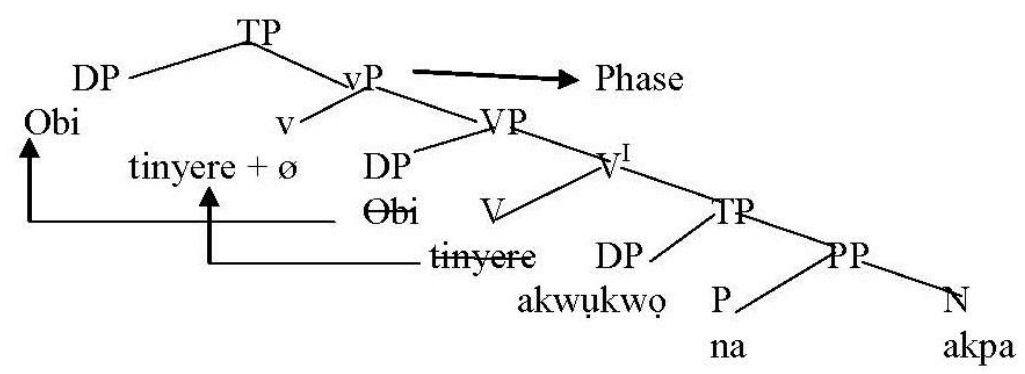

Fig.1

Since the structure above is a transitive one, it is a phase structure. The spell out is the spec of the DP. The probe which is valued for [+past] finds the appropriate goal in the complement of the verb. The phi-features are in order and the structure converges. The V of the V-bar adjoins the causative light verb $\varnothing$ and the spec of the VP adjoins the spec TP. The causative light verb tinyere checks the external DP for nominative case and the internal DP for accusative. The movement takes place during the derivation; else, the structure will crash at both the phonological and logical interfaces. After these movements, there are transfers of the traces left behind and the traces receive null spell outs.

In (4b) below, the selection process is faulty because the Theta Role Assignment Principle, (TRAP) which asserts that theta roles can only be assigned under a Merge operation, is violated when the verb tinyere encode the human NP Uche as the head of the complement of the structure. The resultant violation of operation Select leads to the ungrammaticality of the structure. The structure crashes at both the PF and LF interfaces.

b. * Obi tinye- re Uche kà ọ́ rúsie ọ́rụ íke

Obi put Past Uche for Uche work work hard

Obi put Uche for Uche to work hard

Another instance of verb subcategorisation is witnessed in (5a) below.

(5a) Obi kwàgide- re Uche ka ọ rụsie orụ ike

Obi persuade Past Uche for Uche work work hard

'Obi persuaded Uche for Uche to work harder'

[TP[DP.Obi][VP[V.kwagidere[TP 2 [DP.Uche][CP[C.ka[TP 3 [DP.ọ[VP[V.rụsie[NP[Nọrụ[Adv.ike]]]]]]]

The structure contains both $\mathrm{CP}$ and transitive verb, so the structure is a Phase derivative one. The spellout is located at the TP of the CP. Since Uche of the DP of the TP2 c-commands and binds the DP of the TP3 under the CP, there is no Phase Impenetrable Condition (PIC) since the syntax of the DP of the CP is accessible to the DP of the TP2. This happens because the complement DP of the verb blocks the PIC from obtaining in the structure but the verb must, as cooccurrence relation dictates, c-commands it. The probe continues to search for goals in the matrix TP structure. The DP Obi gets checked by the VP kwagidere for nominative case and the object Uche of the DP of the TP2 for accusative. Since the probe and the goal agree, the structure is well-formed.

In (5a) above, the processes of selecting and merging are in order. The verb kwagidere (persuaded) encodes the right complement. In the structure (5a) under TRAP, the subject has theta role of [persuader] and the complement has the theta role of [persuade]. TRAP ensures that the merger of the V and the DP complement Uche converges. The V-bar on the other hand merges with the subject Uche. The common thing between the persuader and the persuadee is that both share in rationality. In other words, the persuader has the ability to persuade and the persuadee also has the rationality of being persuaded. This is because the verb theta marks its complement but the V-bar theta marks their subject. The violation of TRAP condition on sentence structure accounts for why the (5b) counterpart is ungrammatical. In (5b), the complement cannot be assigned the theta role of [persuadee] because it lacks the ability of being persuaded. Therefore, both the subject and the complement do not both share in rationality and hence the non-convergence of (5b). In this 
structure (5a), the operation select is duly carried out and hence the well-formedness of the structure. Since operation Select enhances the operation merge, the resultant effect is that the structure converges at both the PF and LF interfaces.

b. * Obi kwàgide- re ákwụkwọ n' àkpa

Obi persuade Past book Prep (in) bag

'Obi persuaded book inside the bag'

The (5b) is ungrammatical because the operations Select and Merge are violated in line with TRAP dictates.

It is clear that we need a subcategorisation of word level heads on the basis of complements they take. This is known as the head- complement rule and is formulated as follows:- $\mathrm{X}^{\mathrm{I}} \mathrm{X}, \mathrm{YP}^{*}$. This rule embodies the assumption advocated in Jackendoff (1977) and Stowell (1981), that complements are always maximal projections. E.g.

(6) a. Obi gbù- ru Uche

Obi kill Past Uche

'Obi killed Uche'

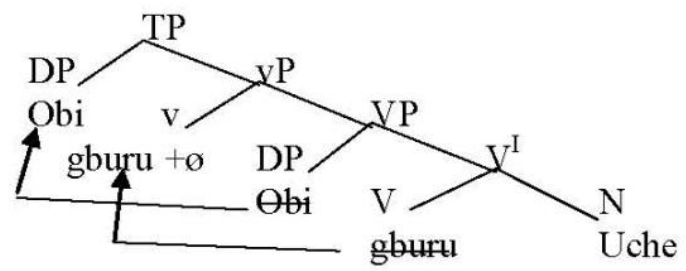

Fig. 2

Since the structure above is a transitive one, it is a phase structure. The spell out is the spec of the V-bar. The V of the V-bar adjoins the causative light verb $\varnothing$ and the spec of the VP adjoins the spec TP. The causative light verb gburu checks the external DP for nominative case and the internal DP for accusative. The movement takes place during the derivation; else, the structure will crash at both the phonological and logical interfaces. After these movements, there are transfers of the traces left behind and traces receive null spell outs.

b. Ưzọ tinye- re ákwụkwọ n'àkpa

Ưzọ put Past book Prep bag

'Uzọ put the book in the bag'.

The (b) structure above follows the same analysis as that of (a) above.

The subcategorisation frame is a format that stipulates what is expected to enter into any slot left open by the presence of the verb which precedes the slot. Subcategorisation frame is a checker against mismatch or discordant relationship between the subcategorisands and their complements. The subcategorisation frames in (7) below is the representative of the example (6a-b) above. E.g.

(7)i. [ _ DP ]

ii. $[$ - DP, PP]

The explanation of the subcategorisation is done in line with the principle of theta criterion which stipulates thus:

(8) "Each argument is assigned one and only one theta role or each theta role is assigned to one and only one argument". (Chomsky 1981,36, Radford 1997,180) E.g.
a. V NP: Okee gbù- ru éwu
Okee kill Past goat
'Okey killed a goat'
b. V NP PP: Ụzọ tinye re akwwụkwọ n’ akpa
Ưzọ put Past book Prep (in) bag
'Uzọ put the book inside the bag'

Because the structure (a) is a transitive one, it is a phase structure. The valued [+past] verb finds the appropriate goal in the object of the verb. The phi-features of the structure receive the valuation of the goal to fulfil its phi-features. Since every probe must agree with the goal, the criterion is met and the structure converges. The subject is checked for a nominative while the object is checked for accusative.

Following the principle of theta criterion, the verb gburu ewu in (9a) theta marks the subject as a killer and the object as the killed. Due to the fact that the verb is a transitive one, it uses a complex verb phrase comprising an inner vP shell headed by the agentive light verb $\varnothing$ (with a causative sense) and an outer VP headed by the verb gburu with the head verb gburu raising to adjoin to the light verb. This implies that the structure "Okee gburu ewu" (Okey killed a goat) is interpreted to imply that Okee's activity caused death to the goat. Operations Select, Merge and Move are well motivated and the structure converges at both the PF and LF interfaces.

The structure (9b) involves a ditransitive verb tinyere or what could be described as a 'double object structure. The analysis of phase structure as is the case of (9a) obtains here. In the structure above, following the ideas put forward by Larson (1990); Hale \& Keyser (1994) and Chomsky (1995); the V-bar head merges with the abstract causative light verb $\varnothing$ with a causative interpretation as a verb like 'make'. The verb tinyere (put) raises to adjoin to it producing a 
structure which can paraphrased as Uzo made the book to be inside the bag , that is, Uzo caused the book to be inside the bag. The resulting V-bar is then merged with the subject Uuọ (which is assigned a nominative role by the causative light verb to form a complex vp ). Subsequently, the vP merges with an abstract $\mathrm{T}$ to form T-bar, and the subject Uzọ raises to spec TP to check its nominative case. (It should be noted that in minimalism, subjects are generated at the VP specifier and then raised to TP specifier which is the highest node up the tree).

In addition, the verb 'tinyere' theta marks its complement 'akwụkwọ' for accusative and at the same time theta marks its subject 'UZzọ' as nominative. (In fact, what theta mark the subject is the entire V-bar). The preposition 'na' theta marks its complement 'akpa' for accusative in accordance with TRAP. So the verb checks the subject for nominative and the object for accusative in the same way that the preposition checks its object for accusative.

In the same vein, verbs select TRAP according to the co-occurrence restrictions and the thematic roles. For instance, a transitive verb which has two verbs - the light verb and the null verb theta marks both the subject and the object differently. The verb theta marks the object internally but theta marks the subject externally. What this means is that not only the verb that theta mark the subject but the V-bar. E.g.

(10) a. Okee gbù ru ágụ

Okee kill Past lion

'Okey killed a lion'

b. Okee gbù- ru ósisi

Okee kill/cut Past tree

'Okey cut down a tree'.

(Refer to the phase analyses in (6a \& 9a) above for (10-12). The complements of the verb - agu and osisi determine the status of the subject and the true nomenclature of the verbs in question. If we choose the kill nomenclature, then sentence (10b) would crash in line with TRAP. If we choose cut then the first sentence (10a) will crash. Based on the fact that a verb must co-occur with certain complements which ensures their grammaticality, there are two different verbs Kill and Cut for the two structures. Again, in as much as the two complements are direct objects, the two objects do not have the same theta roles of killed. The (10a) has the theta role of killed while (10b) has the theta role of cut. The same applies to the subjects which are both seen as nominatives; (10a) is the killer wheras the (10b) is the cutter. In (10a), the verb assigns theta role of killed to 'agụ' and that of killer to 'Okee'. The vP shell that encodes the causative verb makes (10a) paraphrasable as 'Okee's activity caused death to the lion'. This happens because the lion has breathing organ that can be cut short as a result of certain activity. In (10b), the verb 'gburu' will encode a wrong object in 'osisi' (tree) if it means kill. The V-bar theta marks the subject as an Agent but does not theta mark the object as a killed but rather as a cut because a tree does not possess the organ of breathing that can be cut short. So the structure is illformed for kill but wellformed for cut. We can go ahead to analyse the third aspect of the verb in respect to another object or complement.

(11) a. Okee gbu- ru mmadu.

Okee kill Past person

'Okey killed a person'

Here 'mmadu' is the complement of the verb as well as the Patient. The subject is also the Agent of the verb. Since the V-bar externally theta mark the subject, the subject is designated a "murderer". Here the verb theta marks the object as murderee and theta mark the subject as murderer.

Based on the aforementioned, the verb 'gburu', even though is a transitive verb that encodes objects will have its semantic import the moment an object is chosen for it. The issue of dumminess is apparent in the declension of the verb 'gburu'. Again the same verb can be seen to mean 'cut' even when a human entity is the object.
b. Okee gbu- ru Obi mma
Okey kill past?/ cut Obi knife
[Okey injured Obi with a knife].

Here the verb 'gburu' theta marks the complement, the object for cut and the subject for cutter; yet the vP shell of the causative makes the structure to be paraphrasable as 'Okee's activity caused a harm to Obi. The issue of death is not witnessed in the structure. Based on this, the activity is that of cut and not that of kill even though the V-bar assigns the theta role of nominative to the subject and the verb theta marks the object complement for accusative. The subject is not seen in this sentence as a murderer neither is the complement seen as a murderee.

The concept of co-occurrence restriction has shown that a particular verb could have different nomenclatures based on the complement it encodes. Also of note is the fact that the complement of the noun/noun phrase determines the nomenclature of the noun. E.g.

(12) Okee nụ̂- rụ okee mmaị.

Okee drink Past big wine

'Okey drank excessive alchohol'.

The complement of the noun 'nụrụ' and the V-bar 'oke mmaị' designate the subject as a drunk. Since drink is an intransitive verb, all the actions in the sentence structure reside with the subject as the drinker that gets drunk. TRAP ensures that mergers follow due processes in order to generate a convergent structure. In TRAP, both the assigner and the assignee must have something in common. 


\section{A. Reflexive Complementation}

In the Igbo language, some verbs can subcategorise the presence of reflexive complements. The reflexive pronouns in Igbo are ònwé $m$ (myself), onwe gị (yourself), onwe há (themselves), onwe ưnụ (yourselves), onwe anyị (ourselves).

Great number of verbs especially those that require inherent verb complements (IVC) fill these slots. The verbs include the following: kwà, tà, mà, wọ, mesi, pịa, le, me, tinye, gwa, kwado, gụpụ, nyere, jide, gosi, nwapụta, dọpụta and so on. The semantic imports of these verbs are determined by the complements they take. It could be a concrete object or an inherent verb complement. E.g.

(13). a. Há kwà- ra ònwé há émò

3 pl push Past Refl 3pl mock

'They mocked themselves'

b. Ứnụ mèsi- ri ònwé únụ íke

$2 \mathrm{pl}$ do Past Refl 2pl strong

'You suffered yourselves'

c. Ó gbù- ru ònwé ya

3sg kill Past Refl 3sg

'S/he killed her/himself'

Reflexives obey the c-command on binding which stipulates that a bound constituent must c-command by an appropriate antecedent. One of the structures above can be analysed using a tree diagram as below.

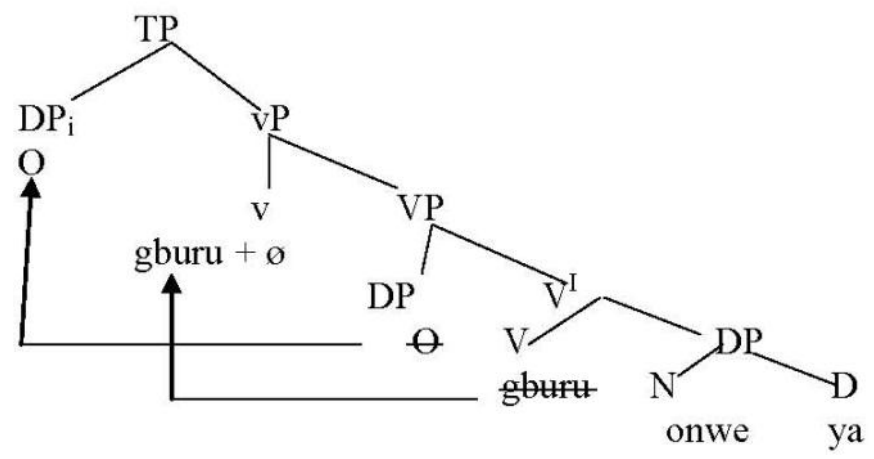

Fig. 3

The relevant bound constituent is the reflexive anaphor 'onwe ya' above; and its antecedent the third singular pronoun ' $\mathrm{O}$ '. The reflexive onwe ya can be bound by the $\mathrm{DP}_{\mathrm{i}} \mathrm{O}$ above because the sister of the DP node is the VP node, and the DP onwe ya is contained within the relevant VP (by virtue of being of the grandchildren of VP). Consequently, the DP ' $\mathrm{O}$ ' c-commands the anaphor onwe ya and the binding condition is satisfied.

Since the structure is a transitive one, it is a phase. The valued probe searches for a goal which it c-commanded. This goal is found in the anaphor onwe ya and the probe does not waste time in agreeing with it since +past probe agrees with any object or goal. Since the probe is valued and the goal is unvalued, the probe agrees with the goal to fulfil its phi-features. This ensures that the structure is well formed and therefore converges at both phonological and semantic interfaces. Once this happens, the moved items undergo transfer. After the transfer, the traces left behind by the moved items receive null spell outs.

All the verbs listed above can be used with all personal pronouns provided that the subject encodes the appropriate reflexive. For instance, ụu must encode onwe unu, mụ: onwe m, anyị : onwe anyị, gị: onwe gị, ha: onwe ha. It will be ungrammatical and unacceptable, for instance, to have a mismatch concord like:

(14) a. * Anyị pịá- rà onwe únù ùtarí

$1 \mathrm{pl}$ flog Past Refl $2 \mathrm{pl}$ cane

'We flogged yourselves'

b. * Ó tinye- re ònwé ụnù na ńsògbú

3sg put Past Refl 3pl Prep trouble

'S/he put themselves into trouble'

The ungrammaticality and unacceptability of (14a-b) above is due to the fact that there are discordances between the subjects and the anaphors (reflexives) they encode. This discordance violates operations Select, Merge and Agree. In (14a), the first plural subject takes a second plural anaphor reflexive complement thereby violating the rule of subject/reflexive concord which could be seen as violation of operations Merge and Agree. What this means is that onwe unu is not the suitable anaphor for the antecedent anyi because the second plural unu cannot be bound by the first plural anyị. It is therefore unbound and hence the ungrammaticality of (14a). The same thing applies to the sentence (14b), where the third singular subject takes the third plural reflexive complement. By virtue of the mismatch the 
binding rule is violated. The violation of the binding rule also violate the rules of operation, select, merge and agree of subject-anaphor agreement (reflexive) which must be co-referential.

\section{B. Infinitival Complementation in Igbo}

In Igbo, infinitives are derived immediately the prefix $i$ or $i$ is attached to the root-verb depending on the principles of agreement and computation. Infinitives act as either noun or verbs depending on the places of their appearances. If they occur at the subject position of a sentence, they are regarded as nouns whereas if the occur at the middle of a sentence structure, they are regarded as verbs. Verbs that encode infinitival complements in Igbo are usually verbs of forward looking. This accounts for the reason why infinitives are futuristic in nature and as such, cannot encode accomplished sentences. The infinitive prefix $\mathrm{i}$ or $\mathrm{i}$ can be attached to any verb-root but the difficulty lies in the appropriate verb that can trigger infinitives since not every verb has the ability to encode infinitival complementation. Few verbs that can trigger/subcategorise infinitival complementation include: bịara (come), chọrọ (want), kpebiri (decided), gburu (kill), e.t.c.

Infinitivals complements are control structures. The reason is that the subject of the matrix verb is also the subject of the infinitival clause. The computation entails that the subject must c-command the infinitival clauses. The operations select, merge and agree are structural and any violation of the structural pattern will render the structure ill-formed.

(15). a. Uche bịa ra [PRO ị́- kpọ́ Okee]

3sg come Past PRO INF call Okee

Uche came [PRO to call Okey]

b. Anyị jụ̂- rụ [PRO ị- kpọ Okee]

2pl refuse Past PRO INF call Okee

'We refused [PRO to call Okey]'

c. Anyị ga- a- gbali [PRO ị- la ụlọ echi]

2pl Aux Pref. try PRO INF go home tomorrow

'We will try [PRO to go home tomorrow]

Examples (15a-c) above show that the various verbs listed above encode the infinitival complements. One thing that is apparent in the choice of the verbs that subcategorise the infinitival complements is the principle of co-occurrence restriction. The principle ensures that the right verb selects the right complement as the tree structure below suggests.

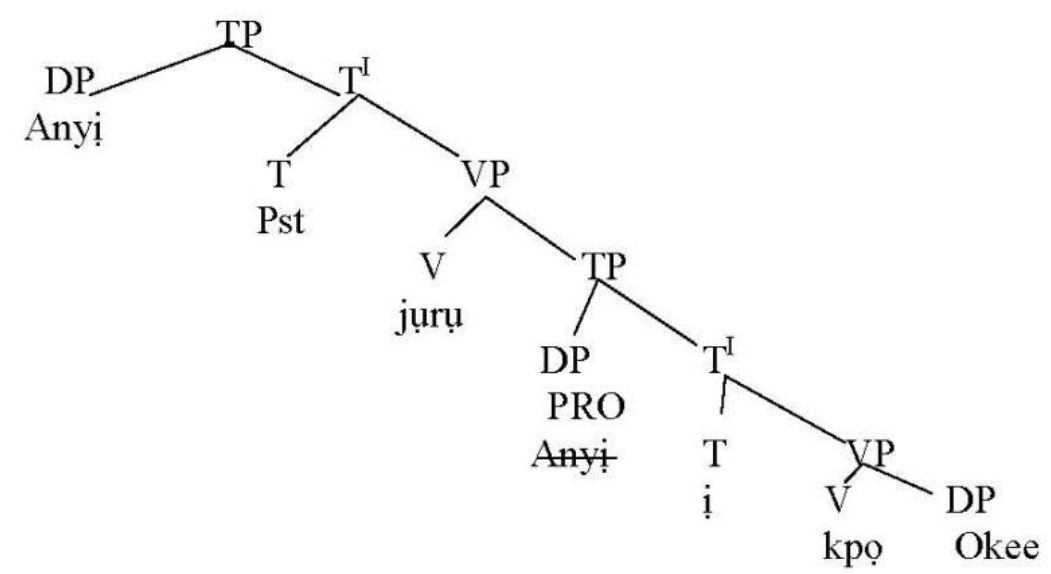

Fig. 4

In control structures, according to Radford (2004), the argument is that apparently subjectless infinitive clauses contain a null subject. The particular kind of null subject found in the bracketed clauses in (15a-c) above have the same grammatical and referential properties as a pronoun, and hence appears to be a null pronoun. The null PRO subjects above is controlled by or refers back to the subject 'anyị' of the matrix clause or equivalently, that 'anyị' (in case of b above whose tree is drawn above) is the controller or the antecedent of PRO; hence a structure like "ọ́ gbalịin PRO ị́la ụ́lọ " (he tried to go home) has an interpretation akin to " o gbalịị ya ịla ụlọ" ( he tried himself to go home). In control structure such as the one above, the PRO is the null subject of the infinitival 'illa' 'to go'. Again, the VP needs a merger with the functional $\mathrm{T}$ to check the past tense feature borne by the verb. This movement of the verb from $\mathrm{V}$ to $\mathrm{T}$ justifies the shortest move principle. So the $\mathrm{T}$ gives the verb its interpretable feature as [+past].The thematic property of the verb 'gbalịị' [tried] in (c) assigns theta role of trier to its subject; hence it requires as its subject an expression denoting a capable being. This entails that the verb theta marks its subject as an entity capable of trying.

The general postulation is that control clauses have silent subjects. If this is so, then a finite auxiliary has an [EPP] feature which requires it to have a subject specifier since the auxiliaries belong to the category $\mathrm{T}$ of tense marker. The same is true of the infinitive 'to' which also belong to T category (by virtue of its status as a nonfinite tense marker). So the broader generalisation is that not only a finite $\mathrm{T}$ but also a nonfinite $\mathrm{T}$ containing the infinitive particle 'to' has an 
[EPP] feature and hence must likewise project a subject (Radford, 2004). The analyses (15a-c) above are consistent with this basic generalisation. E.g.

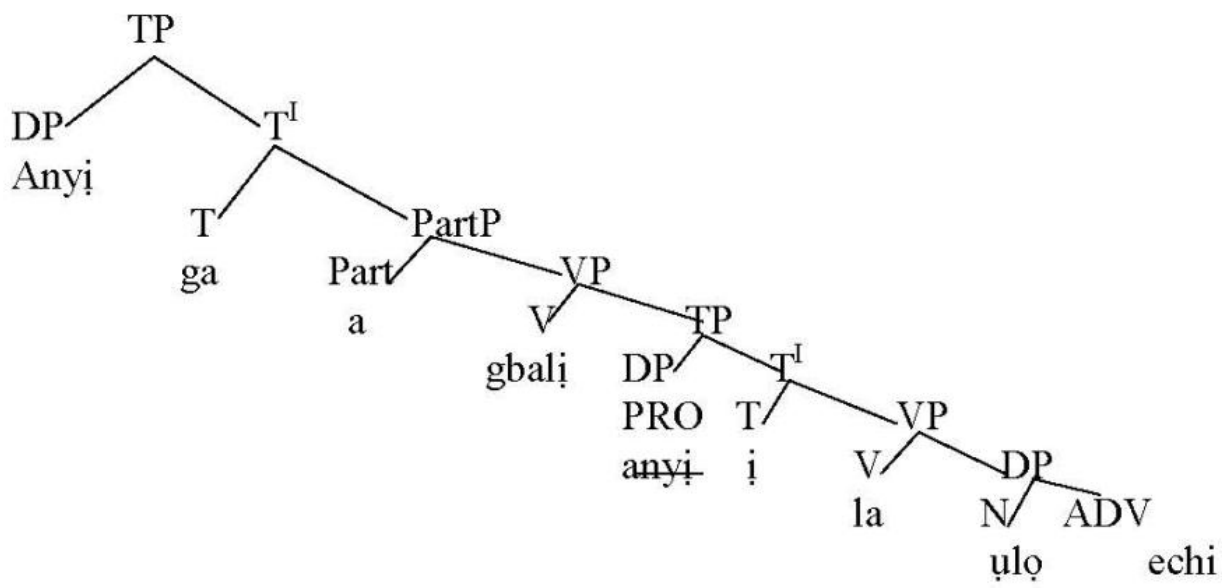

Fig. 5

Figure ( $4 \& 5$ ) above show that the antecedents are the same as the controllers of the infinitive (PROs). This is why the PRO could be represented by the appropriate pronoun as that of the subject in accordance with the generalisation above. Since PRO is invisible to the phonological and logical interfaces, it undergoes transfer and thereafter receives a null spell out in the two interfaces.

\section{FINDINGS AND CONCLUSION}

\section{A. Findings}

In the study of verbal complementation, using Minimalist perspective, the study discovered that the verbs select the types of complements they will co-occur with. The co-occurrence restriction means that every head verb must be linked with complements, which agree with it, therefore, the rule of verb complementation in Igbo is purely that of adjacency and c-command. By adjacency, the head verbs must be adjacent to their complements according to the principle of shortest move in minimalism. C-command entails that the head must precede the complement and thereby c-commands it. The head verb does not need to be far away from the complement it c-commands. By this, there shall not be an intervening node between the head and the complement. The concept of theta criterion determines the theta role to assign to any argument. The V-bar (the complement) determines the exact nomenclature of the subject. A head must establish a path of relationship between it and its environment. Essentially, the meanings of the complements are contained in their heads, but the meanings of the heads are not contained in the complement. The head and complement establish a path of union and intersection in the syntactic form.

\section{B. Conclusion}

This study has investigated different aspects of verbal complementation using Minimalist perspectives. Syntactically, complementation obeys some syntactic rules. These rules are: theta criterion rule, adjacency rule, c-command rule, computation rule and subcategorisation restriction rules among others. Semantically, the heads must choose the complements to co-occur with in line with co-occurrence restriction dictates. This entails that the meanings of the structures must be ranked highest when the combination and computation are considered, because the failure to do that will result in ill-formed and ungrammatical structures. The argument structure of the verb determines the type of complement and the nature of the complement. The verb gives the relevant nomenclature to its satellites. When there is a mismatch in the selectional properties of the verb, the result is ill-formed sentence structure. This mismatch suggests that the computational processes are faulty. This entails that the operations Select and Merge are violated and the resultant effect is ill-formed structure which fail to converge at both phonological and logical interface.

\section{REFERENCES}

[1] Aser, R.E. (1994). The encyclopedia of language and linguistics. London: Pergomon Press

[2] Authier, J-M. (1991). V-governed expletives, case theory, and the projection principle. Linguistic inquiry22, 4:721-740.

[3] Authier, J-M. (1992). Iterated CPs and embedded topicalization. Linguistic inquiry 23, 2:329-336.

[4] Bokin, A. (1993). To be and not to be. Papers from the $9^{\text {th }}$ regional meeting of the Chicago linguistic society. 44-56.

[5] Bolinger, D. (1968). Entailment and the meaning of structures. Glossa 2, (2)119-127.

[6] Bolinger, D. (1973). That's that. The Hague: Mouton.

[7] Bolinger, D. (1974).Concepts and percept: two infinitive constructions and their vicissitudes. In Phonetic Society of Japan (ed). Papers in phonetics: Festscript for Dr. Orishi Kizyu: Tokyo Phonetic Society of Japan. 
[8] Borjars, K. \& K. Burridge (2010). Introducing English grammar. $2^{\text {nd }}$ Edition. London: Hodder education, Hachette U.K company.

[9] Bresnam, J.W. (1979). Theory of complementation in English syntax. New York: Garland.

[10] Carnie, Andrew. (2007). Syntax: A generative introduction. $2^{\text {nd }}$ Edn. Oxford: Blackwell.

[11] Chomsky, N. (1981). Lectures on government and binding. Dordrecht: Foris.

[12] Chomsky, N. (1986a). Barriers. Cambridge: CUP

[13] Chomsky, N. (1986b). Knowledge of language, its nature, origin and use. New York: Praeger.

[14] Chomsky, N. (1995). The minimalist program. Cambridge: MIT Press.

[15] Chomsky, N. (1999). Derivation by step. MIT occasional papers in linguistics 18 [Revised version published as Chomsky (2001)]

[16] Chomsky, N. (2001). Derivation by step. In M. Kenstowicz (ed). Ken Hale: A life in language.(Pp 1-52), Cambridge: CUP.

[17] Chomsky, N. (2002). On nature and language. Cambridge: Cambridge University Press

[18] Dixon, R.W (1991). A new approach to English grammar, on semantic principles. Oxford: Oxford University Press.

[19] Dixon, R.W (1995). Complement clauses and complement strategies. In F.R.Palmer (ed). Meaning and grammar. (Pp174-220), Cambridge: Cambridge University Press.

[20] Duffley, P. (1992). The English infinitive. London: Longman.

[21] Emenanjo, E. N. (1975a). The Igbo verbal. Unpublished M.A. Dissertation, University of Ibadan.

[22] Emenanjo, E. N. (1975b). Aspects of the Igbo verb. In F.C.Ogbalu \& E.N Emenanjo (eds). Igbo language and culture, vol.1 (Pp160-173). Ibadan: Oxford University Press.

[23] Emenanjo, E. N. (1978). Elements of modern Igbo grammar. Ibadan: Oxford University Press.

[24] Emenanjo, E. N. (2005). Igbo verbs: Transitivity or complementation? In O-M Ndimele (ed). Trends in the study of languages and linguistics in Nigeria. A festschrift for Philip Akujuoobi Nwachukwu (Pp. 479-497), Port Harcourt: Grand Orbit communication and Emhai Press.

[25] Frajzyngier, Z. (1991). The dicto domain in language. In T.E.Closs \& B Heine. (eds). Approaches to grammaticalization. Vol.1 (Pp219-251). Amsterdam: John Benjamins.

[26] Frajzyngier, Z. \& R. Jasperson (1991). That clauses and other complements. Lingua 4, 83: 133-153

[27] Finch, G. (2000). Linguistic terms and concepts. London: Macmillan Press. Online version @ www.scrigroup.com.

[28] Gildea, G. (2002). Probalistic models of verb argument structure. In proceedings of the $17^{\text {th }}$ international conference of Computational linguistics. Milan, Italy.

[29] Givón, T. (1980). The dividing hierarchy and the typology of complements. Studies in language 4, 3: 333-372.

[30] Givon, T. (1985). Ergative morphology and transitivity gradients in Newari. In F. Plank (ed). Relational typology. Berlin: Mouton

[31] Hale, K and S. Keyser (1994). "Constraints on Argument structure" Heads, projections and learnability. In M Lost et.al. (eds) Pp53-71, Eribaum: Hillsdale

[32] Hooper, J.B. (1975). On assertive predicates. In J. Kimbal (ed). Syntax and semantics 4. (Pp.91-124) New York: Academic press.

[33] Hooper, P.J \& S.A.Thompson, (1980). Transitivity in grammar and discourse. Language 56 (251-299)

[34] Horie, K. (1993). A cross linguistic study of perception and cognition verb complement: A cognitive perspective. Unpublished doctoral dissertation, University of Southern California.

[35] Horie, K. \& B. Comrie, (2000). Introduction. In K. Horie (ed). Complementation: Cognitive and functional perspectives. (Pp.110) Amsterdam: John Benjamins.

[36] Hornstein, N., J. Nunes \& K. Grohman. (2005). Understanding minimalism: An introduction to minimalist syntax. Cambridge: CUP

[37] Jakendoff, R. (1977). X' syntax: a study of phrase structure. Cambridge: MIT Press.

[38] Keown, K. (2012). What is complementation? A three part explanation. www.tacoma.uw.edu|TLCServices\Handouts\GrammarlGrammar-Complementation Parts_A_B_C. accessed 22-06-2017. Also available on www.languagelinguistics.com.

[39] Kipasky, P. \& C. Kipasky. (1970). Fact Progress in linguistics. In M Bierwisch \& K.E. Heidolph (eds) (Pp143-73). The Hague: Mouton.

[40] Kirsner, R.S \& Thompson, S.A (1976). The role of pragmatic inference in semantics. A study of sensory verb complement in English. Glossa 16, (2) 200-240.

[41] Larson, R. (1990). Double object revisited: reply to Jackendoff. Linguistic inquiry 21: 589-632.

[42] Lehman, C. (1988). Towards a typology of clause linkage. In Haiman, J. \& S.A.Thompson (eds). Clause combining in grammar and discourse (Pp181-225) Amsterdam: John Benjamins.

[43] McCarthy, D. (2000). Using semantic preference to identify verbal participation in role switching. In proceedings of the $1^{\text {st }}$ NAACL. Washington, U.S.A.

[44] Ndiribe, M. O. (Argument structure of the Igbo verbs: An interlanguage analysis). Published in Journal of Linguistics, Language and Literature (Ebonyi State University, Abakaliki, Nigeria) 2018

[45] Ndiribe, M. O. (The concept of the Igbo verb-roots: A functional analysis). Published in Revitalization of African Languages. A festschrift for Professor O-M Ndimele edited by Taiwo, O., F. Ogunkeye, \& H. Adeniyi, (Linguistic Association of Nigeria) 2017

[46] Ndiribe, M. O. (2016). The emergence of ónyé in Igbo. Journal of Linguistic Association of Nigeria (JOLAN) Vol 19, no. 1.

[47] Nwachukwu, Philip.A. (1976). Noun phrase sentential complementation in Igbo. Unpublished Ph.D. Thesis, London: School of Oriental and African Studies.

[48] Nwachukwu, Philip.A. (1983). Transitivity. In P.A. Nwachukwu (Ed). Readings on the Igbo verb (Pp.99-120), Onitsha: Africana-Fep Publishers.[ Available partly online @www.docplayer.net.] 
[49] Nwachukwu, Philip.A. (1984). Towards a classification of Igbo verbs. In P.A Nwachukwu (ed). Readings on the Igbo verbs. (Pp.18-44) Onitsha: Africana-Fep Publishers.

[50] Nwachukwu, Philip.A. (1987). The argument structure of the Igbo verbs. (Lexicon project working papers18). Cambridge, Massachusetts: Center for Cognitive Science, MIT.

[51] Nwankweagu, Jeremaiah.A. (2015). Microparametric syntax of interrogatives in North Eastern Groups of Igbo dialects. A Ph.D preliminary findings. University of Nigeria, Nsukka

[52] Obiamalu, Greg.O. (2015). Functional categories in Igbo: A minimalist perspectives. Port Harcourt: Linguistic association of Nigeria in collaboration with M\&J Grand Orbit Commumication.

[53] Okeke, Chukwuma. O. (2015). Cognitive domains of sense relation of selected Igbo verbs. A Ph.D preliminary findings. University of Nigeria, Nsukka, May, 2015. [Revised version published jointly with Benjamin Igbeaku as "Igbo verb of cooking: A lexical analysis"]. Language Matters, 2015.

[54] Olaogun, Simon. (2017). "A minimalist analysis of focus construction in Njò-kọọ". A paper presented at the $30^{\text {th }}$ Linguistic Association of Nigeria (LAN) conference, $4^{\text {th }}-8^{\text {th }}$ Dec. [Online @www.jolanjournal.com].

[55] Radford, Andrew. (1997). Syntax: A minimalist introduction. Cambridge: Cambridge University Press.

[56] Radford, A, (2004). A English syntax: An introduction. Cambridge: Cambridge University Press. [Parts of the book could be accessed online @ http//.epdf.pub; www.public.asu.edu; www.ediscipline.usp.br; and http//.studentsrepo.um.edu.my.]

[57] Ransom, E.N. (1986). Complementation, its meaning and form. Amsterdam: John Benjamins.

[58] Riddle, Evelyn. (1974). Some pragmatic conditions on complementizer choice: papers from the $11^{\text {th }}$ Regional meeting of the Chicago Linguistic Society. 467-474

[59] Rizzi, Luigi. (1990). Relativized minimality. Cambridge: MIT Press.

[60] Rosenbaun, P.S. (1967). The grammar of English predicate complement constructions. Cambridge: MIT Press.

[61] Ross, John.R. (1973). Nouniness. In O. Fujimura (ed). Three dimensions of linguistic theory. (Pp137-258) Tokyo: TEC.

[62] Stowell, T. (1981). Origins of phrase structure. Ph.D dissertation, MIT.

[63] Uwalaka, A. A. (1983). Motion verbs. In P.A Nwchukwu (1983) (ed). Readings on the Igbo verb. ( Pp.145-167), Onitsha: Africana-Fep Publishers

[64] Wierzbicka, A. (1988). The semantics of English complementation in cross-linguistic perspective. In A. Wierzbicka (ed). The semantics of grammar. (Pp 23-168), Amsterdam: John Benjamins

Matthew Onyebuchi Ndiribe is a Nigerian from Anambra state, South-East Nigeria. Currently, he lectures at the Department of Linguistics, Igbo and other Nigerian languages, University of Nigeria, Nsukka (UNN). He holds B.A (Linguistics) in 2004, M.A in (Linguistics) (Syntax) 2009 and Ph.D also in (Linguistics) (Syntax) 2018 all from UNN. He specialises on Syntax and Semantics but has interest in other branches of linguistics like Sociolinguistics, Applied linguistics and Morphology. He has authored many articles among which are:

Ndiribe, M. O. (Argument structure of the Igbo verbs: An interlanguage analysis). Published in Journal of Linguistics, Language and Literature (Ebonyi State University, Abakaliki, Nigeria) 2018.

Ndiribe, M. O. (The concept of the Igbo verb-roots: A functional analysis). Published in Revitalization of African Languages. A festschrift for Professor O-M Ndimele edited by Taiwo, O., F. Ogunkeye, \& H. Adeniyi, (Linguistic Association of Nigeria) 2017.

Ndiribe, M. O. (The emergence of ónyé in Igbo). Journal of Linguistic Association of Nigeria (JOLAN) Vol 19, no. 1, 2016. 